\title{
Addressing Beliefs Surrounding Urban Sustainability: The Need for a Contextual Urban Model
}

\author{
Hailong Ma \\ Coal Science and Industry Group Nanjing Design and Research Institute Co., Ltd. Nanjing, China
}

\begin{abstract}
While talking about practical advancement at city level, nearby administration is perhaps the main factor and can't be avoided among the numerous significant angles; financial aspects, innovation, and climate, as metropolitan maintainability includes staggered administration and complex political elements. Utilizing the hypothesis of contextualism established by S. Pepper, this paper first and foremost considers the significance of 'feasible' and investigates the utilization and more extensive ramifications of the word 'reasonable' all through as conceived by contextualism. While featuring how metropolitan maintainability can be surveyed, this paper scrutinizes explicit strategies for evaluating metropolitan supportability. It endeavors to connect the basic way of thinking of contextualism to the idea of nearby administration as far as metropolitan administration. It then, at that point, investigates the disconnected part of these standards involving the city of Curitiba for instance. Anyway the model of the city of Curitiba demonstrated hard to survey, as there are excessively many variables to consider. It is felt that this contextual analysis is useful as a showing of the possible significance of the context oriented metropolitan model. We accept it impossible that this will be addressed soon, however it is critical to check out it and an answer for this logical inconsistency ought to be focused on.

Keywords: Contextualism; Contextual urban model; Urban sustainability; Sustainable urbanisation; The city of Curitiba

Citation: Hailong Ma, 2018. Addressing Beliefs Surrounding Urban Sustainability: The Need for a Contextual Urban Model. Journal of Sustainable Urbanization, Planning and Progress, 3(1): 7-14. http://doi.org/10.26789/JSUPP.2018.01.002

Copyright: Addressing Beliefs Surrounding Urban Sustainability: The Need for a Contextual Urban Model. (C) 2018 Hailong Ma. This is an Open Access article published by Urban Development Scientific Publishing Company. It is distributed under the terms of the Creative Commons Attribution-Noncommercial 4.0 International License, permitting all non-commercial use, distribution, and reproduction in any medium, provided the original work is properly cited and acknowledged.
\end{abstract}

\section{Introduction}

Feasible advancement started as a contravention to quick financial development and the improvement of industry and innovation in created nations during the 1960 s and 1970s. There have been various endeavors to characterize reasonable advancement through talk and exploration (Blewitt, 2008) both previously, then after the fact the World Commission on Environment and Development (i.e., The Brundtland Commission) which characterized economical improvement as: "Advancement which addresses the issues of the present without compromising the capacity of people in the future to address their own issues" (The Brundtland Commission, 1987: 8). As a term, practical improvement's regularizing deliberation has generally impacted various specialists, associations and different organizations all over the planet (Gladwin, 1995: 876). Ideas of practical improvement focusing on an ideal future or better world have been created through dreams, evolving values, moral advancement, the re-systemisation of society, or conversional process (Gladwin, 1995: 876). Pertaining to a desired future, there are many serious and urgent issues worldwide to address. Urbanisation is one of these problems (UN- HABITAT, 2011).

Sustainable urbanisation, as a concept, has raised numerous questions, such as: How can we know a city is sustainable? Is urban sustainability always measurable? Do we need an urban model in pursuit of a sustainable city? These are interesting and important questions that need answering in pursuit of sustainable cities. Cities are composed of people's main habitats in the contemporary world, playing a critical role in the discourse of sustainable development. Also, when discussing sustainable development at city level, local governance is one of the most important factors and cannot be excluded among the many important aspects; economics, technology, and environment, as urban sustainability involves multilevel governance and complex political issues (Bulkeley and Betsill, 2005). In attempting to answer these questions, 
this paper will firstly consider the meaning of 'sustainable' and critique the use and wider implications of the word

'sustainable' throughout envisaged by contextualism. Contextualism is "a philosophical worldview in which any event is interpreted as an ongoing act inseparable from its current and historical context" (Fox, 2008: 55). Contextualism deals primarily with "the event in its setting" (Pettigrew, 1985). It is described as the relationship of parts to the whole (Wolford, 2005).

While highlighting how urban sustainability can be assessed, this paper will critique specific methods of assessing urban sustainability, including urban sustainability indicators. After looking at the philosophy underlying these measurable criteria, it will attempt to link the critical philosophy of contextualism to the concept of local governance in terms of urban management. Although contextualism has been widely discussed and has contributed to the epistemological development of research philosophy (Madill et al., 2000), there does not seem to be much research regarding how contextualism has contributed to social development and its major function in contemporary times. Therefore, it is necessary and considered to be important to look at how contextualism has affected social development, specifically focusing on local governance and the issue of sustainability. Finally, it will argue for the consideration of different contexts of time and space in the application of universally accepted principles, by looking into the contradictory aspect of these principles using the city of Curitiba, a frequently stated model of sustainable city, the capital of the State of Paraná, Brazil, as an example.

This paper will look at contextualism as it is outlined in the book World Hypotheses: a study in evidence written by Stephen C. Pepper, a philosopher and aestheticist. Pepper depicts contextualism in his book World Hypotheses as finding the essence of the universe in the synthesised historical, yet changing, event. The word 'historical' is used not in the common sense (to indicate the past), but in a sense that these events keep changing and refer to both precursors and future consequences. In this dynamic and dramatic actuality, a historical event actually means an active event; Pepper (1942) calls this an "act" (p. 232).

Despite the book being published in 1942 and Pepper focusing on the arguments of his own time, the book is amazingly contemporary. Pepper's theory has greatly influenced various subjects from developmental and industrial psychology (Bornstein and Lamb, 1999; Payne, 1996), to qualitative research methods (Pettigrew, 1985), and group theory (Fambrough and Comerford, 2006). To date, for urban studies, Pepper's writing can still be re- discovered, full of insights of the contemporary world.

\section{Overview of Pepper's Contextualism and Conceptual Development}

Within contextualism, a series of historical events show a textual quality as a result of an interdependent process of spread, change and fusion of strands and the context of texture. A spread, also called as a specious present, refers to a paradoxical intuitive "feeling of futurity" (Pepper, 1942: 239) as well as "a corresponding feeling of pastness" (Pepper, 1942: 240) of a given event. A change, the opposite concept of "absolute permanence or immutability" (Pepper, 1942: 243), refers to the continuous shallow temporality that a quality is thought to have, while a fusion refers to an extended meaning of a change, a deeper degree of qualitative integration in an event (Pepper, 1942: 244). Quality refers to the total meaning whereas texture refers to details and relations which make up that quality (Pepper, 1942). Although it is difficult to distinguish between a strand and a context, Pepper (1942) notes that whatever directly contributes to the quality of texture can be regarded as a strand, whereas whatever indirectly contributes to it can be regarded as context.

"Qualitative confirmation theory" (Pepper, 1942: 275), the truth criterion of contextualism or the Contextual Operation Theory (Yim and Lee, 2010), provides a contextualist approach to seek a solution to a problem when a problem arises or to evaluate theories and knowledge claims. When a contextualist is blocked by a problem, she seeks a solution to solve the problem by analysing the situation in search of a hypothesis and by a direct verification of the hypothesis through perception. This is followed by operational act; which in total will lead her to the solution of the problem, the status of satisfaction (Pepper, 1942: 269). This 'Problem Solving Process' can be departmentalised into several steps: Blocking - Analysis - Hypothesis - Perceptual Verification, or Operation - Satisfaction (Yim and Lee, 2010). Through the operation of a hypothesis through direct or perceptual verification, a large amount of insight can be given in terms of the quality and texture that the problem or the event is referred to (Pepper, 1942: 278). It is noted that Pepper's framework can be very valuable in revealing the essential ingredients, assumptions, and concerns of different study fields, and for this reason his work has been recently reintroduced in many areas (Fox, 2008: 56).

\section{3. "Sustainable" and Contextualism}

"Sustainable" in general means "able to be maintained 
at a certain rate or level" (Oxford dictionaries) but it seems to contain various additional meanings with a surplus of social roles in the field of sustainable development which are "fraught with contradictions" (Redclift, 1987), and therefore confusing (Redclift, 1994: 17). At times, the word 'sustainable' seems intended to make a phrase appear smart or stylish when used with other words, and this creates a great deal of argument and confusion. Sometimes 'sustainable development' is confused with "smart growth" or creating "livable communities" (Portney, 2003). By examining a wide range of literature, Frazier (1997) notes 'sustainable' being used as “[a] fashionable modifier" (p. 183). He also indicates that, quite often, the use of the word is even "redundant, hence rendered absurd", in attempts to emphasise it (Frazier, 197: 183). The word 'sustainable' seems to contain the different values that each concept implies, but expresses these in an abstract and seemingly trendy way. Within this tendency, it is also noted that the word sustainable is considered to describe something objective and scientific (Lélé and Norgaard, 1996). Above all, a shared feeling that a sustainable thing is "a good thing" (Beatley and Manning, 1997: 3) appears to exist. After all, there are few who would be against non-sustainable things (Jamieson, 1998: 184). The definition of 'sustainable' is obviously a huge concern to the field (Haughton and Hunter, 2003) and it is something that will continue to produce debate, and be of interest to everyone involved.

To return to the fundamental meaning of the word sustainable as taken from the dictionary, in the previous chapter, the concept of an act is depicted not as "an act conceived as alone or cut off [but] it is an act in and with its setting, an act in its context" (Pepper, 1942: 232). A contextual perspective towards 'sustainable' contains this concept of an act. Focusing on revealing an implicit understanding of the word sustainable from the perspective of contextualism, the authors will attempt to describe this by using qualitative confirmation theory as an example.

According to the articulation of the process of Contextual Operation Theory, an act in its context can be realised by the direct verification of a hypothesis, or perception (Pepper, 1942). While a problem is satisfactorily solved through a contextual act, which is the perception, or the total perceptual verification process of hypothesis, some new textual quality is created. Therefore, we are now situated in a new present with redefined truth. When this new historical present of an event is blocked again by a new strand it creates an unusual sense of surprise that is a novelty, another contextualist problem solving process starts and this process of redefining truth continues.

Through this continuous process named the "Qualitative Circle" by Yim and Lee (2010: 19), "the truth is changeable and becomes continuously new" (Yim and Lee, 2010: 20). Hence, "the ineradicable contextualistic categories may thus be said to be change and novelty" (Pepper, 1942: 235). Nevertheless, since the textual quality embraces layers of pastness as well as futurity that hold through strands and context interpenetrating each other, the new change and novelty come with a sense of "an integrative novelty.. [which institutes] a new strand through fusion, and has new causal potentialities" (Pepper, 1942: 260).

\section{Contextual Principles of Sustainable Cities and Urban Sustainability}

Building on the contextualist meaning of the word sustainable, changing and novel textual qualities being alive at present while also intertwined with the past and future in retrospect through the qualitative circle, lie at the heart of the concept of sustainable cities. By applying this perspective of sustainable cities, some principles of sustainable cities from existing literature may perhaps need to be reconsidered with more focus on the qualitative aspects of urban sustainability.

Modern development and urban domains have been facing problems and alternative plans have been sought (McHarg, 1969). The contested concept of sustainable development can be seen as being in the same line to seek an alternative. Today, more attention is paid to quality within the discourse of urban life, which was discounted by an emphasis on quantitative and objective approaches to urban situations (Lee, 1999; Yim and Lee, 2010); for example, a focus on urban residents' quality of life or a greater social mix in neighbourhoods striving to combat exclusion were set through Agenda 21 launched in Rio and the Third International Urban Forum in Vancouver in 2006 (Lieberherr-Gardiol, 2008: 333). When considering the field of contemporary urban studies, the word 'sustainable' seems to more and more imply a respect for quality in its meaning.

This point can be further supported by the notion of urban sustainability considered as "a problem described by the complex dynamics of human-nature interactions", which requires the perspectives of both scientific and philosophical understandings of the world (Du Plessis, 2009: 31); in other words, an integrated view of the perspectives of quantitative and qualitative approaches to assess urban sustainability. This is important, especially when bearing in mind the fact that urban sustainability indicators are claimed to be more quantifiable and 
scientifically valid than to be accepted by a qualitative form (Bell and Morse, 2003). In attempts to assess how sustainable a city is, and the characteristics of urban sustainability, many different criteria and indicators must not be ignored (Li et al., 2009; Shen et al., 2011). Urban sustainability indicators can be defined as "bellwether tests of sustainability and reflect something basic and fundamental to the long-term economic, social or environmental health of a community over generations" (Sustainable Seattle, 1993: 4). Many have attempted to accomplish an "objectively verifiable scientific measurement of sustainability" (Bell and Morse, 1999: 195). Most criteria or indicators attempt to integrate the different perspectives of stakeholders, and they are based on the fundamental 'scientific' principles of simplicity and quantification (Harger and Meyer, 1996). As Maclaren (1996) also outlines, it is important to note that most indicator systems are to some extent simplification and reflection of complex phenomena, even though some indicators have very complicated multilateral categories. For example, the United Nations (2007) published the new revised edition of the Commission on Sustainable Development (CSD) indicators developed in response to decisions by the CSD and the World Summit on Sustainable Development in 2002. The CSD indicators are composed of 14 CSD indicator themes with 44 subthematic categories. In the past, the Oregon Progress Board identified 272 indicators (Oregon Progress Board 1991). The Alberta Round Table on Environment and Economy finalised a total of 59 indicators from the initial 850 suggestions (Alberta Round Table on Environment and Economy 1994).

While these urban sustainability criteria or indicator systems are broadly applied as important tools (Shen et al., 2011: 26), there is a more fundamental question: Is urban sustainability always measurable? This question echoes the contextualist view on urban sustainability, met by Maclaren's (1996) emphasis on urban sustainability indicators being the simplification of complex phenomena. Two main streams about the question can be found: a moderate perspective, and a radical perspective.

A moderate perspective does not oppose the idea that urban sustainability can be measured, but emphasises that an epistemological shift of the philosophies underpinning urban sustainability is needed for example from the neoclassical economic approach to donor-side approach (Federici et al., 2003). It is important to acknowledge this type of shift when it is applied, because if unnoticed, this may result in inconsistencies in results due to the different scales of time and space as well as the aims of their use (Federici et al., 2003: 156). An attempt to make an indicator system reflect qualitative data by converting to quantitative numeric data can be included in this moderate view as well (Bell and Morse, 2003). Some may see this as quite desirable, as an effort to embrace quality in the indicator system; this may raise a more radical issue of "measurability".

Despite numerous attempts to measure urban sustainability, scholars with a radical perspective like Bell and Morse (1999) challenge the principle of "measurability" regarding sustainability indicators: They argue that these attempts to quantify sustainability are "the impossible task...to measure what was never potentially measurable: the immeasurable "sustainability" (p. 195). The inherent tension between "the physical and social/ psychological, the objective and the subjective" seems to make it difficult to measure sustainability in certain areas such as the quality of people's urban life (Vries et al., 2009: 1008). These types of quantitative approaches are still arguable, but where did they originate?

\section{The Contextual Approach Underpinning Urban Sustainability}

\subsection{How did We Get Here? From Rationalism to Contextualism}

These quantification attempts for urban sustainability evaluation, are thought to have originated from scientific reductionism which "rejects ideas about the reality and importance of unscientific aspects of life... The universe is seen through empiricism as fixed, knowable, measurable and, therefore, predictable" (Bell, 1996: 63). Lawrence (2000) explains this using the term rationalism, which has been a central theme in western philosophy since the Greeks acknowledged reason as "the" superior human characteristic.

Despite its "logical, consistent, and systematic" thinking process (Lawrence, 2000: 610), and the fact that important findings based on rationalism are, for example "land degradation and declining agricultural productivity... greenhouse gas emissions... and loss of biodiversity" (Meppem and Gill, 1998: 124), the philosophy was greatly criticised by contemporary thinkers (Greener, 2011) especially regarding planning theory. As Lawerence (2000: p. 610) outlines, this criticism can be seen as resulting from rationalism's: autocratic tendencies ("professionals and experts" dominate this process with only a peripheral role for the public); overestimation of the ability to predict and control environments; insufficient consideration of creativity, of synthesis (compared to analysis) and of nontechnical and non-scientific knowledge, experience, and 
wisdom (scientific, technical, and quantitative bias). It is further noted that it failed to consider the collective nature of planning and the central role of dialogue; it failed to consider inequities and the political nature of planning (may reinforce inequities); it failed to combine substantive issues such as social and environmental needs and to design the process to suit contextual features; and it failed to consider resource and rational limits.

More science-intensive urban sustainability indicators nowadays attempt to involve human or social factors (Hezri and Dovers, 2006: 91), for example "community indicators, with an emphasis on policy procedures and processes, [mark] a 'critical turn' for the broader indicator literature. Underpinned by the logic of deliberative communication, scholars are exploring the connection to other non-state actors". In this transition process, the UN recommends further work on indicators at the national level in line with each country's conditions and priorities and asked the international community to support the efforts of developing countries in this regard (UN, 2007: 3).

What is required today is thought to be a "participatory and subjective approach" (Bell and Morse, 1999: 195) or the perspective of contextualism. This way of thinking, partly shown through debates with regard to incrementalism (Braybrooke and Lindblom, 1963; Benveniste, 1989; Sager, 1994), a governance model using small steps (Bruyninckx et al., 2012) leads us to a focus on local governance in terms of urban sustainability, as it provides room to look at the interdependency of everything to everything else and the importance of the participating actors in cities. Given that rationalism is largely associated with the natural environmental sciences (Green, 2011) it would seem that another philosophy would be more beneficial to contemporary debates on urban sustainability.

\subsection{The Potential Impact of Contextualism on Lo- cal Governance}

Contextualism is thought to provide more intuition towards good local governance as the notion can control its focus by remaining at a smaller scale of a given event. In terms of definition, local governance can be defined as "the formulation and execution of collective action at the local level" (Shah, 2006: 1). It involves both official institutions that belong to local government, as well as the different types of unofficial arrangements such as "informal norms, networks, community organizations, and neighborhood associations in pursuing collective action by defining the framework for citizen-citizen and citizenstate interactions, collective decision making, and delivery of local public services" (Shah, 2006: 2).
On the other hand, good local governance, although difficult and debatable to define (Graham et al., 2003: 3), is not only "a function of the structure of intergovernmental relationships", but more widely "a result of new opportunities and resources, the impact of leadership motivation and choices, the influence of civic history, and the effect of institutions that constrain and facilitate innovation" (Grindle, 2007: 3). Critical principles in pursuit of good local governance promote participation; consensus orientation; strategic vision; responsiveness; effectiveness and efficiency; accountability and transparency; equity and rule of law (UNDP, 1997). Again, however, in reality, to execute a task at a local level requires a complex set of interdependent relationships with government, local organisations, stakeholders and citizens (Stoker, 2011: 17).

The relationship between contextualism and local governance can be seen through "disorder" (Pepper, 1942: 234), which contextualism accepts, it is shared by interpretivist perspectives seeking to "understand the complex world of lived experience from the point of view of those who live it" (Schwandt, 1998: 221). By welcoming different ideas about a situated and chaotic urban reality and accepting a widened view towards participatory actors of urban governance, contextualism concerns indirect contributors as well as direct contributors regarding an event. In doing so, contextualism can lead us to creativity in disorder, a creation of more mobile and flexible principles. This fits the specific principles of good local governance such as participation and social inclusion by bridging the, beyond criticism, bottom-up approach of experts- dominant processes in rationalist planning theory, and celebrating tacit knowledge in knowledge management and capacity building in the local community (Pratt, 2008).

However, with this 'active citizenship', it must be also noted that there is a possibility that only wealthy and professional middle-class people will be able to participate in a pluralist governing system, and this will only result in another form of elitism (Kearns, 1995). Moreover, because of this, some of the national governments' distrust towards both local government and the 'amateur', shows a tendency to prefer "the use of paid directorships" in the public realm (Kearns, 1995: 159), and this distrust may also leave the education of citizenship to become "obligations" in schools, not rights (p.159).

Despite concerned voices, to make 'Think Global, Act Local', a slogan, which is attributed to Patrick Geddes (1915), operational, a critical approach to different local contexts seems necessary. Successful stories of local governance that benefit people in society can 
be found in many southern and developing countries, while their qualities and natures may be different (Stoker, 2011). Although there are sarcastic views on these publicised successful stories being 'sold for their cities' competitiveness, supported by messages from active campaigners (Gilbert, 2006), it seems undeniable that there are many lessons to be learned from these pioneering examples. Among many cases, an example from Latin America is of particular interest because of its historical context and unique application in terms of local governance.

\section{Good Local Governance and Its Relation- ship with the Concept and Role of Leader- ship: The Case of the City of Curitiba, Brazil}

Even though in the 1970 s, Latin America was dominated by military regimes, after experiencing the so-called 'Third Wave Democratization' (Huntington, 1991), most nations are based on free democratic election supported by neoliberalism, decentralisation, local democracy and the promotion of participation (Gilbert, 2006). However, not every city seems to have followed the basic principle of promotion of participation. As such, the city of Curitiba, the capital of the State of Paraná, Brazil, has been celebrated as a successful example and model of a sustainable city with a vision of a city for people. In many international competitions for sustainable cities, the city of Curitiba has been recognised significantly, for example, winning the Globe Sustainable City Award 2010 for excellent sustainable urban development and the Sustainable Transport Award 2010 for the implantation of the Linha Verde (Green Line). Nevertheless, it has also been criticised at the same time, due to the exclusiveness of citizen participation. In other words, the clear interconnected strategies in urban planning, intensely supported by strong leadership with powerful and influential visions, were one of the key factors for success towards urban sustainability. However, the process mainly led by professionals and specialists, has resulted in exclusion regarding popular participation (Irazabal, 2005).

In terms of strategy, Curitiba has put great emphasis on people and integrated planning and these strategic points affect most of the dimensions of the city (ICLEI, 2003). Beginning in the 1960s in the Urban Planning Institute of Curitiba (IPPUC), Curitiba's urban plan is still on-going in the third phase today (Potal da Prefeitura de Curitiba). The clear strategic vision encompassing all urban dimensions of the city can be revealed by its visionary former mayor, Jaime Lerner, who was involved from the city's Master Plan in 1965 and led the city's transformation and served as the city's mayor three times:

"There is no endeavour more noble than the attempt to achieve a collective dream. When a city accepts as its mandate its quality of life; when it respects the people who live in it; when it respects the environment; when it prepares for future generations, the people share responsibility for that mandate, and this shared cause is the only way to achieve that collective dream" (ICLEI, 2003: 2).

This fact can be seen as being in line with one of the principles for good governance, "strategic vision", which entails that: "leaders and the public have a broad and long-term perspective on good governance and human development, along with a sense of what is needed for such development. There is also an understanding of the historical, cultural and social complexities in which that perspective is grounded" (Graham et al., 2003: 3). A strong institution that will sustain their vision with "a group of well-trained specialists controls the process of land use and transportation very much in tune with developers in order to provide a 'comfortable' environment for a population that in exchange would have no reason to challenge the political status quo" contributed to the city's achievement towards sustainability as well (Lara, 2010: 119). Lara (2010) further notes that this aspect of professionalism was the reason why the city has become celebrated as a model city in the First World.

While this can be seen as an alternative approach with fundamental but innovative vision and leadership to foster sustainable cities, it seems obvious that the principle of 'strategic vision' reinforced by strong leadership, conflicts with the principle of participation. Although it can be advocated through the legitimate processes of a local democracy, it does not seem to touch citizens' deep perceptions towards critical values, for example the social inclusion that decentralisation promotes. From a contextualist viewpoint, this can be regarded as an ignorance of a critical context underlying the historic event.

Irazabal (2005) stresses that: "the city's marketing efforts have built up citizen pride as an uncritical, irresponsible social conscience that supports the status quo of the structure of power and the dominant social class' (p. 100). Lara (2010) made this point evident by noting that "electoral data [shows] that Curitiba has consistently voted more conservative than other Brazilian capitals and even to the right of smaller cities in the state of Parana", with an additional explanation that more progressed larger cities show a tendency of more votes for the left (p. 119). This reinforces what Millband (2008) argues that: "Political change comes from leadership and popular 
mobilisation. And you need both of them" (Ed Miliband, UK Secretary of State for Climate, December 2008).

Many years of serving as the mayor of the city as well as the president of the IPPUC for a long time are undeniable factors in the city's recognition as a sustainable city - this strength in leadership can be seen as fostering the city's urban transportation system as one of Curitiba's best-known planning achievements, an international model for implementation of well- integrated systems with environmental benefits. Considering that transport is one of the traditional sectors that are thought to require central provision with appropriate infrastructures (Gilbert, 2006), it seems that the success could have been difficult without such a sense of powerful leadership.

Such leadership can also be seen differently from the contextualist perspective of Wood (2005) who argues that leadership is an event and a process. Wood (2005) stresses that it is not a property of a person or of an organisation, but it cannot exist without "any reference to a social context or to some communistic processes" (Wood, 2005: 1114). According to Wood's view, which is shared by contextualist notions, Curitiba's leadership can be seen as successful only within the specific given context of time and space with the involved social actors. It can be inferred that personal or organisational qualities regarding leadership can be continued for a long time, therefore can be called desirable, and can be varied by context. Consequently what constitutes leadership is good and accordingly sustainable also seems arguable.

\section{Conclusions}

The concept of a sustainable city is contested and debatable. Despite skeptical views of the mal- operational functions of the word 'sustainable', it seems only obvious that with great influential power, it has brought a big change in the history of the contemporary world and more is to be expected when considering the dramatic progress within the political, social, economic and environmental contexts. Although many initiatives and principles are given at different levels in the world of sustainable development, they do not always appear to be on common ground, or to be more precise; this common ground does not seem to exist yet. There are various reference points, but most importantly, critical interpretation and application considering local situations and contexts are thought to be necessary. Through this process, the contextual implication of the word sustainable respecting the qualitative roots of urban dynamics seems to open up a wide window from which to explore qualitative discourse on urban sustainability.

As shown in the example of the city of Curitiba, the contradictory principles of good local governance and how well these principles are applied at a local level are arguable. It seems unlikely that this contradiction will be solved in the near future, but it is important to look at, and a solution to this contradiction should be aimed for. Due to different historical and socio-cultural contexts, a critical application of the principles through the primary process of extensive examination regarding the different urban situations of each urban domain is necessary (Sasaki, 2010). Also, more in depth case studies on different cities will follow in future research in order to overcome the limitation that this paper may hold.

Urban sustainability is a contested concept to approach. However, it is thought to be truly beneficial to look at existing ideas towards urban sustainability, and challenge them to be more integral, bearing this fact in mind with regard to the application of any apparently good models. A model refers to "a thing used as an example to follow or imitate" (Oxford dictionaries, 2012). To use an example of a city as a 'model' seems debatable. It is so because different contexts of history, geography, social, political, economic and environmental dimensions can matter, as well as seeing through the underlying philosophies, in order to carefully and critically contribute to a broader contextual concept of sustainable development. Critical consideration of these different conditions before adaptation is required.

The rationalist follows a traditional philosophy of science, which sees everything as measurable, and can be challengeable. Contextualism, by counteracting the traditional philosophy of science can be beneficial to debates on the qualitative aspects of urban sustainability. It must be noted that it is not that we claim that clear answers now only exist in qualitative methods. Rather, we place our understanding on recognising the philosophical differences of both methods clearly, and are attempting to curve back the current biased view towards quantitative approaches. Above all, this type of philosophical exploration is essential in conceptualising urban sustainability by bringing ontological and epistemological debates down to the practical level.

\section{References}

[1] ACKOFF, R.L (1971). Towards a System of Systems Concepts. Institute of Management Sciences. Providence. RI.

[2] ALBERTA ROUND TABLE ON ENVIRONMENT AND ECONOMY (1991). Alberta: Working for a Sustainable Future. Edmonton: Alberta Round Table on Environment and Economy.

[3] ARONSON, D. (1996). Overview of Systems Think- 
ing. Available at http://www.thinking.net/Systems Thinking/systems_thinking. html. (Accessed on 27 March 2012).

[4] BEATLEY, T., \& MANNING, K. (1997). The ecology of place: planning for environment, economy and community. Washington, DC, Island Press.

[5] BELL, S. (1996). Learning with information systems: learning cycles in information systems development. London, Routledge.

[6] BELL, S., \& MORSE, S. (1999). Sustainability indicators: measuring the immeasurable? London, Earthscan Publications.

[7] BELL, S., \& MORSE, S. (2003). Measuring sustainability: learning by doing. London, Earthscan Publications.

[8] BENVENISTE, G. (1989). Mastering the politics of planning: crafting credible plans and policies that make a difference. San Francisco, Jossey-Bass.

[9] BLEWITT, J. (2008). Understanding sustainable development. London, Earthscan.

[10] BORNSTEIN, M. H., \& LAMB, M. E. (1999). Developmental psychology an advanced textbook. Mahwah, N.J., L. Erlbaum Associates. http:// search.ebscohost.com/login.aspx?direct=true \&sc ope $=$ site $\& d b=$ nlebk $\& d b=$ nlabk \&AN $=24246$.

[11] BRAYBROOKE, D., \& LINDBLOM, C. E. (1963). A strategy of decision: policy evaluation as a social process. London, Free Press of Glencoe.

[12] BRUYNINCKX, H., HAPPAERTS, S., \& BRANDE, K. V. D. (2012). Sustainable development and subnational governments policymaking and multi-level interactions Houndmills, Basingstoke, Hampshire, Palgrave Macmillan. http://www. palgraveconnect. com/doifinder/10.1057/9781137005978.

[13] BULKELEY, H., \& BETSILL, M. (2005). Rethinking Sustainable Cities: Multilevel Governance and the 'Urban' Politics of Climate Change. Environmental Politics. 14, 42-63.

[14] DU PLESSIS, C. (2009). Urban Sustainability Science as a New Paradigm for Planning. Presented at the Smart and Sustainable Built Environments (SASBE 09) Conference, Delft, The Netherlands, 14-19 June.
[15] FAMBROUGH, M., \& COMERFORD, S. (2006). The Changing Epistemological Assumptions of Group Theory. The Journal of Applied Behavioral Science. 42, 330-349.

[16] FEDERICI, M., ULGIATI, S., VERDESCA, D., \& BASOSI, R. (2003). Efficiency and sustainability indicators for passenger and commodities transportation systems. Ecological Indicators. 3, 155-169.

[17] FRAZIER, J. (1997). Sustainable development: modern elixir or sack dress? Environmental Conservation. 24(2) June 1997: 182- 193.

[18] FOX, E. J. (2008). Contextualistic perspectives. In SPECTOR, J.M. (2008). Handbook of research on educational communications and technology. New York, Lawrence Erlbaum Associates.

[19] GEDDES, P. (1915). Cities in Evolution. London: Williams. http:// www.archive.org/details/citiesinevolutio00gedduoft.

[20] GHARAJEDAGHI, J. (1999). Systems thinking managing chaos and complexity: a platform for designing business architecture. Boston, Mass, Butterworth-Heinemann. http://search.ebscohost. com/ login.asp $x$ ?direct $=$ true $\&$ scope $=$ site $\& d b=$ nlebk $\& d-$ $\mathrm{b}=$ nlabk\& $\mathrm{AN}=34001$.

[21] GLADWIN, T. N. (1995). Shifting paradigms for sustainable development: Implications for management theory and research. New York, N.Y., New York University, Leonard N. Stern School of Business.

[22] GILBERT, A. (2006). Good Urban Governance: Evidence from a Model City? Bulletin of Latin American Research. 25, 392-419.

[23] GRAHAM, J., AMOS, P., PLUMTRE, T. (2003). Principles for Good Governance in the 21st Century. http://www.iog.ca/ publications/policybrief15.pdf.

[24] GREENER, I. (2011). Designing social research: a guide for the bewildered. Los Angeles, SAGE.

[25] GRINDLE, M. S. (2007). Going local: decentralization, democratization, and the promise of good governance. Princeton, Princeton University Press.

[26] HARGER, J. R. E., \& MEYER, F-M. (1996). Definition of indicators for environmentally sustainable development. Chemosphere. 33, 1749. 